\title{
O ENSINO DA LÍNGUA PORTUGUESA NO BRASIL PARA FALANTES DA(S) VARIEDADE(S) NÃO PADRÃO DA LÍNGUA
}

\author{
Diana Rodrigues Sarcinelli dos Santos* \\ Lays de Oliveira Joel Lopes* \\ Não bá uma língua portuguesa. Há \\ linguas em português. \\ José Saramago
}

RESUMO: Este artigo tem como objetivo refletir acerca de como ocorre o ensino da variação linguística no contexto da sala de aula e sobre como os alunos se reconhecem, a partir de sua identidade linguística. Para tanto, analisa quatro coleções de livros didáticos que estiveram em fase de análise para uso no triênio 2018-2020 pelas escolas estaduais do Espírito Santo e utiliza um formulário de percepção de língua preenchido por alunos do primeiro ano do ensino médio de uma escola em Viana/ES, a fim de detectar como o ensino de língua portuguesa influencia na identidade do aluno, sobretudo no ambiente escolar. Busca defender um ensino que considere as variedades linguísticas presentes em sala de aula, em que se articule o ensino do português padrão, a valorização e o respeito ao falar diferente dos alunos. Para tanto, utilizamos como vertentes teóricas, para sustentação deste artigo, os pressupostos estabelecidos pela Sociolinguística e a Sociolinguística Educacional, com base nas reflexões de Weinreich, Labov e Herzog (2006 [1968]), Labov (2008 [1972]), Bortoni-Ricardo (2004; 2005) e Bagno (2013).

PALAVRAS-CHAVE: Ensino; Identidade do aluno; Língua portuguesa padrão; Preconceito linguístico; Variedades linguísticas.

\section{Considerações iniciais}

Há muito, o ensino da língua portuguesa padrão nas escolas tem sido pensado como algo maçante e odiado por muitos alunos, talvez porque a língua portuguesa estudada em sala de aula não esteja próxima da língua que os alunos utilizam mais comumente ou porque estão sempre sofrendo coerções toda vez que pronunciam ou escrevem algo “errado", isto

\footnotetext{
* Mestre em Estudos Analítico-descritivos da Linguagem pela Universidade Federal do Espírito Santo (Ufes). Doutoranda pela mesma Instituição. Bolsista CAPES, com participação em Programa de Doutorado Sanduíche no Exterior (PDSE/CAPES) na Texas Tech University (TTU - Lubbock/Estados Unidos).

** Mestre em Linguística pela Universidade Federal do Espírito Santo (Ufes). Doutoranda em Linguística pela mesma Universidade.
} 
é, em desacordo com a norma padrão. Então, percebendo o ambiente da sala de aula como uma arena, em que a língua padrão disputa com variedades linguísticas utilizadas pelos discentes, pretendemos verificar como acontece o tema da variação linguística é abordado em livros didáticos.

Para desenvolver esta pesquisa, analisamos quatro coleções de livros didáticos para o ensino médio, que estiveram sob análise pelo corpo docente das escolas estaduais do ES para serem utilizadas no triênio 2018-2020, a fim de identificar em que período escolar e como o tema da variação linguística é abordado nos livros. Para tanto, acompanhamos o processo de escolha dos livros ocorrido em 2017/2018, em uma escola da periferia de Viana/ES. Além disso, utilizamos um formulário de percepção ${ }^{1}$ de língua preenchido por alunos do primeiro ano do ensino médio na intenção de detectar, ainda que superficialmente, como as metodologias atuais de ensino têm influenciado a identidade do aluno, sobretudo no ambiente escolar. Nossa intenção é refletir como o processo de ensino aprendizagem tem influenciado a percepção que os discentes têm de sua língua materna.

Nossa hipótese é que o ambiente da sala de aula acomoda variedades distintas de língua: a padrão e as não padrão. Pensando nisso, conjecturamos que as variedades não padrão, cotidianamente, utilizadas pelos estudantes não é valorizada no contexto escolar. Isso porque a escola é um ambiente que, institucionalmente, é reconhecido como difusor da norma padrão da língua. O resultado da ausência de uma educação que articule as variedades linguísticas em sala de aula é o preconceito linguístico, uma vez que as não padrão não são consideradas no ensino da língua portuguesa nas escolas, o que pode levar à exclusão social e ainda gerar diversas formas de violência: psicológica, física e verbal.

Neste artigo, refletiremos, acerca da situação linguística no interior da língua portuguesa do Brasil, no contexto escolar, ao descrever como isso ocorre em sala de aula, especificamente, no que se refere ao uso do livro didático, e ao mostrar como o aluno se reco-

\footnotetext{
${ }^{1}$ No anexo A, apresentamos o formulário de percepção na íntegra, tal como disponibilizado aos alunos. No anexo $\mathrm{B}$, evidenciamos as respostas obtidas dos alunos e seu respectivo quantitativo.
} 
nhece diante de diferentes situações sociais, a partir de sua identidade linguística. Para atingir os objetivos pretendidos, utilizamos como base teórica as reflexões de Weinreich, Labov e Herzog (2006 [1968]), Labov (2008 [1972]), Bortoni-Ricardo (2004 e 2005) e Bagno (2013).

Para tanto, este texto organiza-se da seguinte maneira: após estas considerações iniciais, apresentaremos o pressuposto teórico que embasa este estudo, em seguida a metodologia de pesquisa utilizada, as análises das coleções didáticas, os resultados dos formulários de percepção e, por fim, as considerações finais.

\section{Língua, variação e variedades: uma perspectiva da Sociolinguística e Sociolinguís- tica Educacional}

A Sociolinguística - ramo da Teoria Linguística que considera a língua como um produto social e, portanto, passível de variação - emerge na segunda metade do século XX, na década de 1960, com as publicações das primeiras produções de Willian Labov, reconhecido como o pai da Sociolinguística. Destaque também às postulações veiculadas por Weinreich, Labov e Herzog (2006 [1968]) e Labov (2008 [1972]), importantes obras para entendimento dos pressupostos sociolinguísticos.

A vertente nomeada Sociolinguística afasta-se da concepção formalista de análise da língua enquanto estrutura e propõe que se admita a influência de fatores sociais no uso linguístico. Em Labov (2008 [1972]), nota-se claramente o esforço do autor em assinalar a importância dessa área de concentração de estudo, embora não menospreze as contribuições linguísticas promovidas até então:

Existe uma crescente percepção de que a base do conhecimento linguístico na linguística tem de ser encontrada na fala - a língua tal como usada na vida diária por membros da ordem social, este veículo de comunicação com que as pessoas discutem com seus cônjuges, brincam com seus amigos e ludibriam seus inimigos [...]. (LABOV, 2008 [1972], p. 13) 
Parafraseando Oswald de Andrade (1972), notamos que a Sociolinguística se atenta às manifestações da língua falada por "o bom negro" e "o bom branco"2. Entretanto, observamos que, meio século depois, a língua prestigiada continua a ser a "gramática do professor". Objetivando estabelecer um elo entre as produções acadêmicas e as aulas ministradas na educação básica, o ramo da Sociolinguística concebido como Sociolinguística Educacional estabelece como um de seus objetivos: desfazer preconceitos disseminados na própria sala de aula, ambiente que deveria instaurar o respeito, no que tange a todos os grandes temas sócio-históricos. A partir dessa perspectiva, Bortoni-Ricardo (2004) defende que:

No caso brasileiro, o ensino da língua culta à grande parcela da população que tem como língua materna - do lar e da vizinhança variedades populares da língua tem pelo menos duas consequências desastrosas: não são respeitados os antecedentes culturais e linguísticos do educando, o que contribui para desenvolver nele um sentimento de insegurança, nem lhe é ensinada de forma eficiente a língua padrão [...]. (BORTONI-RICARDO, 2004, p. 115)

As pontuações de Bortoni-Ricardo (2004, p. 115), nos permitem refletir acerca da (des)valorização da variedade linguística do educando no ensino básico. Percebemos, portanto, que essa variedade tem sido negligenciada por professores de Língua Portuguesa, assim como os demais docentes e membros da equipe pedagógica e administrativa das unidades escolares. Essa situação alude ainda à formação docente oferecida por universidades, institutos de educação superior e faculdades do país.

\footnotetext{
2 Relacionamos a obra modernista "Pronominais", de Oswald de Andrade (1972), e a corrente sociolinguística, originada nos Estados Unidos. Sabe-se que o Movimento Modernista Brasileiro objetivava a promoção da identidade brasileira por meio de produções literárias motivadas pelas particularidades da Nação e distanciadas dos modelos literários europeus importados até então. Sugerimos como leitura introdutória, a obra "História concisa da Literatura Brasileira", de Alfredo Bosi (2015). Cita-se o belíssimo texto de Oswald de Andrade: "Dê-me um cigarro/ Diz a gramática/ Do professor e do aluno/E do mulato sabido/ Mas o bom negro e o bom branco/ Da Nação Brasileira/ Dizem todos os dias/ Deixa disso camarada/ Me dá um cigarro".
} 
De acordo com Bagno (2013), o problema na formação dos professores de Língua Portuguesa inicia-se já na nomenclatura do curso "Letras", que revela um apego a concepções de educação e à formação de cidadãos datadas do século XIX, reminiscência de um passado que considerava o estudo da língua como algo subjacente, unicamente, à tradição literária clássica. $\mathrm{O}$ autor destaca que:

Com o surgimento da ciência linguística moderna, no início do século XX, poderíamos imaginar que uma grande revolução abalaria essa arquitetura aristocrática, derrubando os velhos templos beletristas neoclássicos, mofados e insalubres, para, no lugar deles, se erguerem edifícios arejados, iluminados, funcionais, onde a ciência poderia transitar à vontade. Nada disso, porém, aconteceu. (BAGNO, 2013, p. 25)

Sendo assim, a existência de um distanciamento entre as produções acadêmicas e a sala de aula é inegável. O linguista ainda pontua o programa dos cursos brasileiros de Letras como algo controverso, uma vez que objetiva a formação de (i) pesquisadores que dominem as correntes linguísticas; e, concomitamente, (ii) a de docentes aptos ao ensino nas diversas modalidades de ensino. Neste contexto, o livro didático - objeto de estudo deste artigo - figura como uma ferramenta essencial para o ensino de língua portuguesa. Esclarecemos que nossa intenção não é a de menosprezar a importância do uso do livro em sala de aula. Entretanto, concebemos que é um suporte, um norteador que deve ser analisado criticamente pelo professor. Contudo, o que vemos é um "círculo vicioso" entre editoras e professores, como afirma Bagno (2013), quando ressalta a produção, a escolha e o uso de livros conservadores em sala de aula. Para este autor "As editoras produzem livros conservadores porque as professoras e professores escolhem livros conservadores, e as professoras e professores - sem formação adequada - escolhem livros conservadores porque as editoras produzem livros conservadores" (BAGNO, 2013, p. 41).

O que vemos, portanto, é uma metodologia em sala de aula que valoriza a norma padrão, ao passo que se despreza as múltiplas variedades da língua portuguesa. Como destaca Weinreich, Labov e Herzog (2006 [1968]), a variação e a mudança são inerentes à língua. Todavia, apenas reconhecer a variação não é suficiente, é necessário compreendê- 
la, estudá-la, de forma a desmitificar preconceitos que circundam alguns fenômenos. Weinreich, Labov e Herzog (2006 [1968]) destacam que o domínio de um falante monolíngue nativo abrange estruturas heterogêneas como parte de sua competência linguística. Assim, nessa abordagem, em uma língua de determinada comunidade complexa, a ausência de heterogeneidade estruturada seria disfuncional.

Reconhecidas as variedades, percebe-se, entretanto, a valoração entre elas. A esse respeito, Bortoni-Ricardo (2004) pondera que:

[...] os falantes que são detentores de maior poder - e por isso gozam de mais prestígio - transferem esse prestígio para a variedade linguística que falam. Assim, as variedades faladas pelos grupos de maior poder político e econômico passam a ser vistas como variedades mais bonitas e até mais corretas [...]. (BORTONI-RICARDO, 2004, p. 33-34)

Diante disso, podemos inferir que eleger uma variedade linguística prestigiada resvala em questões políticas. Diante disso, não é de se estranhar que alunos da classe baixa, como o caso da escola em análise, demonstrem um nítido sentimento de inferioridade, no tocante à língua que utilizam. Isso posto, é de nosso interesse perceber, a partir das análises a seguir, como o tema da variação linguística será tratado nos livros didáticos eleitos para análise e como os alunos se sentem quanto ao ensino de língua portuguesa.

\section{Metodologia de pesquisa}

Para cumprir com o objetivo deste artigo, julgamos interessante tomar como objeto de análise quatro coleções de livros didáticos destinados ao ensino médio, elencadas pelo MEC, que estiveram em fase de análise pelo corpo docente das escolas estaduais do estado do Espírito Santo para escolha da coleção que seria utilizada pelas respectivas escolas, no triênio 2018-2020. A escolha do corpus justifica-se pela percepção de que, embora os Parâmetros Curriculares Nacionais (PCNs) deixem clara a importância do trabalho com variação linguística - o que é algo extremamente positivo - não há uma articulação clara entre a proposta do Ministério da Educação (MEC) e as práticas desenvolvidas em sala de aula. Isto posto, as coleções de livros didáticos que foram disponibilizadas para eleição pelos 
professores da rede estadual e que serão analisadas por nós são as seguintes: Português: contexto, interlocução e sentido, de Maria Luiza M. Abaurre, Maria Bernadete M. Abaurre e Marcela Pontara; Ser protagonista: lingua portuguesa, de Ricardo G. Barreto, Miranka G. Bárbara e Cecília Bergamim; Se liga na língua: literatura, produção de texto e linguagem, de Wilton Ormundo e Cristianne Siniscalchi; e Português: trilhas e tramas, de Ivone Ribeiro et al.

Além da análise das coleções de livros didáticos, também recorremos a um formulário de percepção (ANEXO I), de elaboração própria, como objeto de análise, na intenção de verificar algumas atitudes e percepções de alunos frente à sua maneira de uso da língua e à aprendizagem da língua portuguesa em sala de aula. Acreditamos que dar voz aos discentes é uma tarefa ousada, visto que nos projeta para longe da zona de conforto, desnuda a prática docente e evidencia a amplitude das questões ora discutidas.

Nesse sentido, o formulário de percepção foi estruturado a partir de cinco perguntas, a fim de conduzir o assunto em questão aos alunos: (i) quando você ouve falar em língua portuguesa, quais palavras vêm a sua mente? Escreva no máximo 05 palavras; (ii) o que você acha do ensino da língua portuguesa na escola?; (iii) considerando que você ingressou na escola já sabendo falar português, como você entende a necessidade de estudar o português na escola?; (iv) como você avalia a sua forma de falar em relação ao português ensinado na escola?; (v) você acha importante aprender na escola as diferentes formas de falar o português? Esse formulário foi aplicado a alunos do primeiro ano do ensino médio do turno matutino de uma escola da Rede Estadual de Ensino, localizada no bairro Arlindo Vilaschi, em Viana/ES.

Na constituição deste formulário de percepção, objetivamos refletir acerca das atitudes linguísticas dos discentes em relação a sua própria língua, uma vez que, segundo Grosjean ([1982] 2001, p. 117, tradução nossa): “[...] a língua é acompanhada por atitudes e valores mantidos por seus usuários e também por pessoas que não conhecem a língua $[\ldots]^{3 “ *}$. Nossa intenção, com o formulário, é perceber se há um sentimento de inferioridade 
dos falantes entrevistados em relação a sua variedade de fala, sendo ele um produto dos preconceitos linguísticos que circundam as variedades não padrão. Nossas conclusões serão resultado das observações desses dois objetos - livros didáticos e formulário de percepção - assim verificaremos de que maneira o ensino da Língua Portuguesa, em sala de aula, que, em certa medida, desconsidera as variedades linguísticas não padrão, está contribuindo para a perpetuação do preconceito linguístico e quais são os sentimentos/percepções dos alunos frente a essa situação.

\section{Análise: coleções de livros didáticos}

Esta seção dedica-se a apresentação de nossa percepção quanto às coleções analisadas neste artigo. A escolha dessas ocorreu de forma aleatória e representa um recorte das inúmeras opções disponibilizadas ao processo de seleção de livro didáticos a escolas da rede estadual do Estado do Espírito Santo, por meio do Guia de Livros Didáticos, constante no portal do Fundo Nacional de Desenvolvimento da Educação (FNDE). No curso desta pesquisa, acompanhamos parte do processo de escolha de uma escola situada na periferia de Viana/ES. Os alunos dessa mesma escola foram os voluntários no preenchimento do formulário de percepção, cujos dados estão expostos no tópico sequente.

Ao final desta, evidenciaremos a obra adotada pela escola em análise. Vejamos a seguir.

\section{Coleção 1: Português: contexto, interlocução e sentido ${ }^{4}$}

Esta coleção é dividida em três volumes, de acordo com as três séries do ensino médio (1 $1^{\mathrm{a}}, 2^{\mathrm{a}}$ e $3^{\mathrm{a}}$ série). O tema da variação linguística figura no volume 01 , condizente a $1^{a}$ série do ensino médio. Este volume é dividido em três seções: Literatura, Gramática e Produção de texto. As seções de literatura e gramática apresentam três unidades e a de

\footnotetext{
${ }^{4}$ ABAURRE, Maria Luiza M.; ABAURRE, Maria Bernadete M.; PONTARA, Marcela. Português: contexto, interlocução e sentido. 3 ed. São Paulo: Moderna, 2016.
} 
produção de texto, quatro unidades. Cada unidade, por sua vez, é dividida em capítulos que versam sobre temas relacionados ao conteúdo central da unidade/seção.

Como a primeira parte do livro é dedicada à seção de Literatura, o tema da variação linguística aparece nos primeiros capítulos da primeira unidade (unidade 04) da seção de Gramática, sendo estes o décimo segundo, décimo terceiro e décimo quarto capítulos da ordenação geral da obra. A análise da obra nos permite concluir que, embora seja tratada com mais destaca nos três primeiros capítulos dessa seção de Gramática - 12, 13 e 14 - o tema da variação circunda também as demais unidades da seção gramática. Na apresentação da unidade 04 , as autoras esclarecem:

Nos capítulos desta unidade, você vai conhecer a diferença entre linguagem e língua, descobrir o que são as variedades linguísticas e por que algumas delas são alvo de preconceito. Vai entender, ainda, como o uso que fazemos da linguagem revela tanto sobre quem somos e sobre como vemos o mundo. (ABAURRE, ABAURRE e PONTARA, 2016, p. 127)

Neste trecho, percebemos a preocupação das autoras em desmitificar a questão do preconceito linguístico. Ao longo dos capítulos 12, 13 e 14 - respectivamente, Linguagem e variação linguística, Oralidade e escrita, A dimensão discursiva da linguagem - há uma série de quadros informativos, intitulada "Tome nota”, em que são apresentados conceitos (socio)linguísticos importantes, tais como: interlocutor, linguagem, língua signo linguístico, gíria, jargão, dentre outros. Os capítulos são compostos por uma gama muito diversa de gêneros textuais, que abrange desde tirinhas e charges a placas, propagandas e resenhas curtas de textos clássicos.

As atividades levam o aluno a construir um pensamento acerca dos textos e da linguagem de forma gradual, de forma a considerar o contexto e o gênero textual sob análise. Há uma categoria especial de atividades, destinadas a questões de "Enem e vestibulares", nessas são referenciadas as instituições de onde os exercícios foram extraídos.

Nas unidades 05 e 06, discute-se acerca da Linguagem e Sentido e Introdução aos estudos gramaticais. Essas unidades abordam temas relacionados: a primeira trata de construção lin- 
guística e efeitos de sentido, tal como recursos estilísticos da linguagem; e, a segunda unidade trata da estrutura e dos processos de formação de palavras. Embora esses temas circundem a questão da variação e variedade linguística, em diversos momentos, ao longo destas unidades, esses temas recebem destaque. Um exemplo é o quadro "Cuidado com o preconceito", no capítulo 16, em que é retomado abertamente o tema do preconceito linguístico apresentado no capítulo 12. Citamos ainda a "Seção especial: o português no mundo", no capítulo 18, que também retoma o tema em questão.

\section{Coleção 2: Ser protagonista: Língua portuguesa ${ }^{5}$}

Nesta coleção, a variação linguística também é tratada apenas no volume 1. O tema figura no capítulo 10, pertencente à unidade 6 (Introdução aos estudos sobre a linguagem), que faz parte da segunda seção do livro, que aborda a linguagem (Linguagem: ser no mundo e com o outro). Este capítulo, Uma língua, muitas línguas, discorre sobre variação linguística e apresenta os tipos de variação (regional, situacional, social e histórica). Discute sobre a diferença entre norma padrão, norma culta, erro e adequação linguística. Além disso, o capítulo também ressalta a importância de conhecer diferentes variedades linguísticas. Existe ainda destaque à questão do preconceito linguístico trazido em quadros intitulados Leia e Ação e cidadania. Neste, o preconceito linguístico é explicado e naquele há a sugestão de leitura do livro Preconceito linguistico, de Marcos Bagno. As atividades propostas contemplam o tema apresentado no capítulo, porém sem muito aprofundamento reflexivo.

O capítulo termina com quatro pequenas seções diferentes: Lingua viva, que traz a ideia de que o falante é poliglota em sua própria língua; Em dia com a escrita, que trata do uso do hífen, segundo o novo acordo ortográfico; Articulando, que, a partir do depoimento de um linguista e de um gramático, propõem que seja debatido pelos alunos o tema relacionado à gramática e ao seu ensino; e A lingua tem dessas coisas, que aborda questões de tradução

${ }^{5}$ BARRETO, Ricardo Gonçalves; BÁRBARA, Miranka Gonçalves-Santa; BERGAMIM, Cecília. (Orgs.. Ser Protagonista: língua portuguesa. 3 .ed. São Paulo: Edições SM, 2016. v. 1. p. 158-170. (Coleção Ser protagonista). 
de palavras regionais para outro idioma e traz atividades com vistas a estimular o aprendizado de diferentes expressões e palavras típicas de diferentes comunidades.

\section{Coleção 3: Se liga na língua: literatura, produção de texto e linguagem ${ }^{6}$}

Nesta coleção, o livro que trata da variação linguística é o volume 1, o qual está dividido em três partes: literatura, produção de texto e linguagem. É nesta última parte que a variação linguística é tratada, mais precisamente no capítulo 17, Linguagem e língua, da unidade 9, Linguagem: sistema de comunicação. Posteriormente, o tema da variação linguística é retomado, na seção final da unidade 9, denominada Expressão coletiva.

O capítulo 17 começa trazendo breves conceitos sobre o que é linguagem verbal, não verbal e mista, além de língua e de variação linguística. Nas atividades propostas é que serão abordados, especificamente, os tipos de variação (social, regional, histórica), gírias e jargões. Ao tratar, ainda nas atividades, das variedades linguísticas, sobretudo as variedades urbanas de prestígio, o capítulo faz uma pequena menção ao preconceito linguístico, às marcas de identidade, ao nível formal e coloquial do uso da língua, enfatizando o tema da adequação linguística. Além disso, traz quadros informativo-reflexivos, intitulados "Sabia?", sobre a norma padrão, o uso de certas palavras do léxico, e a interferência destas no imaginário popular; e ainda, um quadro chamado Alguém fala/ escreve assim?, que apresenta a oposição linguagem do homem versus linguagem da mulher, na intenção de estimular os alunos a lançarem um novo olhar para sua comunidade, região, etc.

Na seção denominada Expressão coletiva, ao final da unidade 9, o tema da variação linguística é retomado com o título Caso das faixas de rua de Maringá: discussão da noção de erro. Nesta, lança-se uma proposta de debate em sala de aula e envolve a preparação de uma exposição que será vista pela comunidade. O assunto polêmico que guia o debate é "o lugar que a norma padrão deve ocupar no ensino da língua e na comunicação cotidiana dos fa- 
lantes" (ORMUNDO; SINISCALCHI, 2016, p. 272), bem como a noção de erro. A proposta tem como base dois textos de diferentes posicionamentos. O primeiro texto apresentado Advogado espalha faixas em Maringá para combater vícios de linguagem traz à tona o fato ocorrido na cidade de Maringá - PR, em que o advogado Lutero de Paiva Pereira espalhou faixas nos semáforos da cidade na intenção de "combater" vícios de linguagem, ação produto do projeto Sinal do Saber. A justificativa do advogado é "contribuir com o desenvolvimento cultural da cidade" (ORMUNDO; SINISCALCHI, 2016, p. 73), ao divulgar um conhecimento melhor da gramática. Seu projeto conta com muitos patrocinadores.

Já o texto 2 Em faixas, projeto defende que desobedecer norma culta não é errado, em contraposição ao Texto 1, tem a ver com outro projeto, desenvolvido pela Universidade Estadual de Maringá chamado Virada Linguística, que tem por objetivo a defesa de que não existe somente uma única forma de falar e escrever o português e que ser diferente não é errado. Cristiane Carneiro Capistrano, uma das coordenadoras do projeto, diz que a proposta do projeto não é para criticar o projeto Sinal do Saber, mas "para ressaltar a diversidade linguística e cultural da cidade, além de sensibilizar a comunidade em relação às políticas linguísticas e de letramento" (p. 274).

Após a exposição desses dois textos e de comentários de alguns autores envolvidos com os estudos linguísticos, como Sírio Possenti, Marcos Bagno e Celso Pedro Luft, os grupos de alunos são levados, por meio de perguntas de cunho reflexivo, a definir seus posicionamentos e a realizarem o debate. Na sequência, os grupos são direcionados a prepararem cartazes levando em conta a discussão ocorrida em sala de aula, contemplando também o conceito de variação linguística e a importância de levá-lo em consideração em todas as reflexões relacionadas à língua e a comunicação. 


\section{Coleção 4: Português: trilhas e tramas ${ }^{7}$}

Nesta coleção, o tema da variação linguística é tratado nos volumes 1 e 3, diferentemente das outras coleções. Em ambos os volumes, isto é, em cada um desses livros, o tema em questão é tratado em apenas um capítulo. No volume 1, a variação é tratada no capítulo 17, pertencente à terceira parte do livro, denominada Gramática e estudo da língua. Já no volume 3, o tema é retomado no capítulo 22, na segunda parte do livro, também intitulada Gramática e estudo da língua.

No primeiro volume, o capítulo 17 - Variedades linguísticas - começa com uma sugestão ao professor que inicie uma discussão com os alunos relacionada à norma padrão da língua portuguesa, com base em um trecho do poema de Oswald de Andrade [...] Para telha dizem teia/ Para telhado dizem teiado/ E vão faz̧ndo telhados, inserido no começo do capítulo, e com base nas perguntas inseridas no quadro $\mathrm{Na}$ bagagem, localizado na mesma página, que traz perguntas relacionadas ao que os alunos estudarão ao longo do capítulo, isto é, perguntas que fazem referência ao modo como a língua é falada de norte a sul do país, se poderíamos dizer que falamos uma língua brasileira, etc. As respostas para os questionamentos feitos, os conceitos e as teorias sobre as línguas e sobre a língua portuguesa são trazidos embutidos em um trecho de A língua de Eulália, escrita por Marcos Bagno, que toma quase todo o capítulo. Na sequência, o capítulo traz atividades de interpretação de texto relacionadas ao trecho apresentado inicialmente e termina com outras atividades que abordam o mesmo tema, porém considerando majoritariamente as variações regional e social.

No volume 3, o capítulo 22, Variedades linguísticas II, o tema das variedades linguísticas é retomado. O assunto é abordado por meio de atividades adaptadas do Enem que abordam o tema. Na primeira página do capítulo, assim como no capítulo do volume 1, também é sugerido que o professor inicie um diálogo que leve os alunos a reflexões sobre

${ }^{7}$ RIBEIRO, Ivone; SETTE, Graça; STARLING, Rozário; TRAVALHA, Márcia. Português: trilhas e tramas. 2. ed. São Paulo: Leya, 2016. v. 1. (Coleção Trilhas e tramas) 
a língua e são revisados, em um parágrafo, os conceitos estudados no capítulo 17, do volume 1 desta coleção.

A análise dos livros didáticos nos permite vislumbrar a maneira como o tema tem sido abordado na educação básica regular. Notamos que o tratamento da variação linguística nessas obras apresenta um padrão, em que ao conteúdo são destinados poucos capítulos e, consequentemente, algumas poucas aulas em meio a tantas outras atividades que também necessitam de serem trabalhadas. $\mathrm{O}$ assunto em questão é apresentado nos livros didáticos de forma isolada e conteudista, ou seja, destina-se a ele uma seção metodologicamente organizada, a partir da exposição do tema e da realização de atividades.

Quanto ao processo de escolha do livro didático, no Espírito Santo, este ocorre, em conformidade com as etapas propostas pelo Ministério da Educação (MEC). Dessa forma, mediante a disponibilização do período de registro de escolha dos livros didáticos do Programa Nacional do Livro e Material Didático (PNLD) para as escolas, ocorre a escolha dos livros pelas unidades de ensino participantes do processo. Nestas, acontece a análise do Guia de Livros Didáticos, conforme dados do portal do Fundo Nacional de Desenvolvimento da Educação (FNDE). A decisão da equipe escolar deve ser acordada em reunião entre membros da equipe pedagógica e docente da unidade. Em seguida, a gestão da instituição registra as coleções escolhidas, sob a forma de ata, no sistema do Programa Dinheiro Direto na Escola (PDDE). O resultado gerado poderá ser unificado e o material adotado pelas escolas da rede estadual ou por grupo de escolas 8 .

No que se refere ao processo de escolha do livro da escola relacionada neste estudo, esta optou pela obra Português: contexto, interlocução e sentido, de Maria Luiza M. Abaurre, Maria Bernadete M. Abaurre e Marcela Pontara. No que tange ao tema da variação linguística, percebemos que a coleção apresenta avanços, quanto à abordagem do tema, visto que instiga o aluno a refletir sobre a língua, a linguagem, o preconceito linguístico e as variedades

\footnotetext{
${ }^{8}$ Para mais informações sobre o processo de escolha, os sites oficiais do Governo do Estado e Federal poderão ser consultados. Neste artigo, não nos aprofundaremos nessa questão, pois, no momento, o objetivo de nosso trabalho nos insere aprofundadamente no tema da variação linguística e percepção desta pelos alunos.
} 
e variações intrínsecas a língua. Todavia, reconhecemos que essa deveria ser uma tendência de toda a coleção. Consideramos, portanto, que para a efetivação de um processo de mudança de paradigma na percepção preconceituosa que muitos discentes - e também docentes e membros da equipe pedagógica - possuem acerca do uso das variedades não padrão da língua portuguesa, são necessárias estratégias que insiram a variação linguística de forma disseminada em toda a coleção.

Além disso, Abaurre, Abaurre e Pontara (2016) apresentam uma multiplicidade diversa de gêneros textuais que permite ao professor explorar recursos estilísticos e interpretativos no ensino da gramática. Quanto aos conteúdos de literatura, a obra aborda textos literários clássicos, mas sugere opções marginais para que o docente tenha liberdade de trazer diferentes obras para o estudo em sala de aula. Enfim, percebemos que este, como os demais livros analisados, é um suporte para o docente. Sendo assim, defendemos que o livro didático não pode jamais ser início, meio e fim do processo de ensino-aprendizagem, mas deve ser uma ferramenta suporte, entre tantas outras, visto que o docente deve particularizar as metodologias adotadas ao seu público-alvo.

\section{Formulários de percepção}

Como mencionado anteriormente, o formulário de percepção foi disponibilizado a alunos da $1^{\text {a }}$ série do Ensino Médio Regular, de uma escola da Rede Estadual, localizada em Viana. O preenchimento do formulário se deu de forma voluntária, individual e não avaliativa. A proposta foi apresentada pela professora ministrante da disciplina de Língua Portuguesa e uma das autoras deste artigo, Lays de Oliveira Joel Lopes, que esclareceu na ocasião que as informações apresentadas pelos alunos seriam utilizadas unicamente para fins de pesquisa acadêmica e possível publicação, de maneira a não divulgar quaisquer dados pessoais e sociais evidenciados pelos discentes. Ressaltamos que, por se tratar de adolescentes em idade inferior a 18 anos, os pais foram comunicados da atividade e assinaram um termo de consentimento.

Obtivemos um total de 43 alunos voluntários ao preenchimento do formulário, os quais se mostraram solícitos e animados com a proposta. Destacaram que gostariam de 
apresentar seu posicionamento em relação a outras disciplinas, e ainda no que tange à prática docente de alguns profissionais. A escola recebe, em geral, discentes das proximidades da instituição. Portanto, os alunos, geralmente, são amigos de infância e conhecem previamente alguns funcionários que também são da região.

O formulário foi constituído em cinco tópicos. Inicialmente, os alunos deveriam responder ao seguinte questionamento: 1) quando você ouve falar em língua portuguesa, quais palavras vêm a sua mente? Escreva no máximo 05 palavras. Coletou-se um total de 197 ocorrências ${ }^{9}$, que em sua maioria revela o apego à tradição gramatical e à literária, uma vez que menciona conteúdos estudados no ensino regular, tais como: acentuação, advérbio, Classicismo, Literatura. Observa-se outro conjunto de palavras que destaca a importância do ensino de língua portuguesa: profissão, educação, necessidade. Além disso, os alunos expuseram sua perspectiva quanto ao ensino: chato, legal, maravilhoso, horrível. Outros mencionaram nomes de alguns professores que, de alguma forma, marcaram, positiva ou negativamente, sua vivência.

Nota-se que os alunos relacionaram "língua portuguesa" à disciplina ensinada na escola, e não a sua língua materna adquirida na mais tenra idade. Apenas duas alunas perceberam a ambiguidade do questionamento e solicitaram à professora esclarecimentos quanto ao objeto alvo do questionário: a língua portuguesa enquanto variedade(s) linguística(s) ou a disciplina escolar. A resposta da docente foi que colocassem o que julgassem melhor. Revisitando o formulário das duas discentes, notamos que ambas optaram por destacar palavras relacionadas ao ensino regular. Diante disso, percebermos que há um distanciamento entre o português ensinado na escola e o falado pelos alunos, de forma que ambos são considerados como objetos indissociáveis.

Nos demais tópicos, os alunos deveriam mencionar: 2) O que você acha do ensino da língua portuguesa na escola?; 3) Considerando que você ingressou na escola já sabendo falar o português, como você entende a necessidade de estudar o português na escola?; 4)

${ }^{9}$ A listagem completa com as ocorrências apresentadas pelos alunos pode ser observada no anexo II. 
Como você avalia a sua forma de falar em relação ao português ensinado na escola?; 5) Você acha importante aprender na escola as diferentes formas de falar o português? Notamos que a maioria dos alunos reconhece a importância de se estudar o português (forma padrão da língua). Apresentaremos, a seguir, algumas das respostas mencionadas pelos discentes:

\section{Excertos:}

Tópico 02: O que você acha do ensino da língua portuguesa na escola?

R.: Uma ótima importância, pois nós, alunos, precisamos saber falar correto, para que no ambiente que vivemos haja sempre um conhecimento.

(Sexo feminino, 15 anos, sem defasagem idade/série)

Tópico 03: Considerando que você ingressou na escola já sabendo falar o português, como você entende a necessidade de estudar o português na escola?;

R.: A necessidade é de escrever certo e aprender novas palavras.

(Sexo feminino, 15 anos, sem defasagem idade/série)

Nos dois excertos, as respostas das alunas evidenciam que a noção de certo versus errado predomina largamente nas salas de aula, ainda que tão criticada pelas Teorias Linguísticas Contemporâneas, em especial, no que se refere à Sociolinguística Educacional. No tópico 03, raros alunos mencionaram que já sabiam o português (sua língua materna). Outros destacaram que é necessário estudar o português, pois, em situações de formalidade, devem usar o "português correto". No que tange à autoavaliação de sua forma de falar o português, notamos que noções preconceituosas, discriminatórias e sentimento de inferioridade emergem.

\section{Excertos:}

Tópico 4: Como você avalia a sua forma de falar em relação ao português ensinado na escola? R.: Fraca, eu não utilizo muito as formas de linguagem aprendidas na escola.

(Sexo feminino, 15 anos, sem defasagem idade/série)

Tópico 5: Você acha importante aprender na escola as diferentes formas de falar o português? R.: Sim, pois sabendo falar bem o português, estamos alcançando o conhecimento e isto é bom. (Sexo feminino, 15 anos, sem defasagem idade/série)

R.: Em alguns casos sim, em outros não.

(Sexo feminino, 15 anos, sem defasagem idade/série)

R.: Não muito, porque não falamos quase nunca do jeito que a escola ensina.

(Sexo masculino, 17 anos, com defasagem idade/série)

R.: Não, até porque não me interesso por isso.

(Sexo masculino, 16 anos, com defasagem idade/série) 
R.: Para que saber isso tudo se com um tempo eu vou esquecer?

(Sexo masculino, 16 anos, com defasagem idade/série)

A maioria dos alunos respondeu que o estudo do português é importante. Apenas uma aluna não se mostrou assertiva ao questionamento. E três alunos, com defasagem idade/série, destacaram que não percebem a funcionalidade do ensino do português na escola. Nas aulas, esses alunos mostram-se desmotivados em relação ao ensino do conteúdo. Isso nos faz refletir até que ponto o ensino é atrativo aos alunos. Além disso, a própria metodologia de ensino pode ser motivadora dos altos índices de reprovação que essa escola especificamente enfrenta.

\section{Considerações finais}

A produção deste artigo possibilitou a reflexão de vários pontos caros ao processo de ensino-aprendizagem do aluno. Um ponto observado é que a sala de aula representa um contexto que comporta variedades distintas de língua, a variedade padrão e as variedades não padrão. Embora estas últimas não estejam sendo consideradas no processo educacional, na maioria das vezes, ela existe na sala de aula às margens da tentativa do ensino do português padrão. Pensando nisso é que conjecturamos a ausência de uma abordagem, sobretudo no contexto escolar, e o resultado dessa educação em sala de aula é o preconceito linguístico.

Outro ponto está relacionado ao fato de uma aluna de 15 anos, sem defasagem idade/série, apresentar o seguinte conjunto de palavras referente ao tópico 01 do formulário de percepção: texto - escritores - texto - atividade - texto. Diante desse e de outros fatos encontrados, foi possível perceber que, embora a escola invista em projetos pedagógicos, recursos audiovisuais, etc., a leitura de textos e a apresentação de escritores renomados, bem como a realização de atividades avaliativas distantes das práticas dos alunos ainda são predominantes no contexto da sala de aula. Esclarecemos que não estamos desqualificando essas práticas, apenas evidenciamos o apego a abordagens tradicionalistas, que parecem ser ainda inevitáveis no processo de ensino-aprendizagem e como estas são percebidas pelos discentes. O impossível é mensurar exatamente o quanto essas práticas são danosas 
ou benéficas à construção do conhecimento pelo aluno, mas é possível termos uma pequena noção a partir desta pesquisa.

Com base nas análises das coleções de livros didáticos, vimos que existe uma tentativa de tratar do tema da variação linguística no contexto escolar do ensino médio, o que é um grande avanço, em especial, na obra escolhida pela escola, cita-se Abaurre, Abaurre e Pontara (2016). Entretanto, tal tentativa não é de todo eficaz, uma vez que não é capaz de abarcar a complexidade do tema da variação linguística.

Percebemos que a variação, por vezes, é tratada de forma isolada e conteudista em grande parte das coleções didáticas. Logo, concluímos que não há uma integração da ideia da variação linguística no conjunto da obra. Pelo contrário, o que existe é ainda uma supervalorização da norma padrão, enquanto o tratamento da variação é visto em um ou dois capítulos apenas. Sendo assim, independentemente da coleção de livros didáticos que os professores escolhem, o tratamento das variedades linguísticas em sala de aula parece ser mínimo, a não ser que o professor regente tenha tido uma formação acadêmica que o preparou para fazer diferente. Caso contrário, a percepção dos alunos em relação à língua permanecerá do mesmo modo e, consequentemente, o preconceito linguístico continuará sendo perpetuado, desvalorizando as variedades linguísticas que "atropelam" a língua portuguesa padrão, segundo senso comum entre muitos professores.

Não estamos dizendo que mais capítulos sobre variação linguística resolveriam a situação que expusemos. Como dito anteriormente, a integração da ideia da variação linguística no conjunto da obra seria uma saída, mas não apenas isso. É preciso a participação ativa do professor em sala de aula, cuja formação lhe tenha permitido refletir criticamente acerca dos assuntos sobre língua/linguagem e que esteja preparado para lidar com as diversidades e adversidades. Reconhecemos a necessidade do ensino/aprendizagem da variedade padrão da língua portuguesa nas escolas, sobretudo por questões sociais, mas acreditamos que não é válido que esse ensino ocorra em detrimento das variedades não padrão da língua portuguesa do Brasil, também devido a questões sociais. Além disso, a valorização das variedades linguísticas dos alunos no ensino da língua portuguesa padrão é uma questão humana, de valorizar o outro, o que vai além de um ensino descritivo/normativo. 
Deixamos para o fim deste artigo um convite à reflexão ao nosso leitor sobre todo sistema educacional brasileiro e capixaba. O preconceito na sala de aula não se deve apenas à prática docente ou às condições socioeconômicas dos alunos que as escolas públicas recebem. Estão implicados nessa tarefa: o Ministério da Educação; as Secretarias de Educação; as Superintendências Regionais de Educação; as Universidades, os Institutos de educação superior e as Faculdades que operam na formação de licenciados; os professores atuantes em sala de aula; as editoras e os autores de livros didáticos que projetam um aluno ideal, que é muito distante da realidade do aluno brasileiro; aos alunos que se acomodam frente às dificuldades do ensino; ao desinteresse de alguns pais, que, devido a uma série de fatores, negligenciam a educação dos filhos, etc. Sabemos que a disseminação de preconceitos e a promoção de um ensino de qualidade é tarefa árdua e complexa. Nossa sugestão é a não acomodação. Todos os processos revolucionários observados na História têm em comum a arduidade e a complexidade. Mas, ao final, constitui-se um resultado importante para o futuro da nação - seja esse positivo ou não, a depender dos caminhos tomados pelos agentes da mudança.

\title{
THE PORTUGUESE LANGUAGE TEACHING IN BRAZIL TO SPEAKERS OF THE NON-STANDARD VARIETY (S) OF THE LANGUAGE
}

\begin{abstract}
This article aims to reflect how the teaching of linguistic variation occurs in the context of the classroom and how students recognize themselves from their linguistic identity. Therefore, it analyzes collections of textbooks that were under analysis for use in the triennium 2018-2020 by the state schools of Espirito Santo and uses a form of perception of language completed by students from the first year of a high school in Viana/ES in order to detect how Portuguese language teaching influences at the student's identity, especially in the school context. It seeks to defend a teaching that considers the linguistic varieties present in the classroom, which articulate the teaching of standard Portuguese, the appreciation and the respect to the different speech of students. Therefore, we used as theoretical strands, to support this article, the assumptions established by Sociolinguistics and Educational Sociolinguistics, based on the reflections of Weinreich, Labov and Herzog (2006 [1968]), Labov (2008 [1972]), Bortoni- Ricardo (2004 and 2005) and Bagno (2013).
\end{abstract}

KEYWORDS: Teaching; Student identity; Portuguese standard language; Linguistic prejudice; Linguistics varieties. 


\section{REFERÊNCIAS}

ABAURRE, Maria Luiza M.; ABAURRE, Maria Bernadete M.; PONTARA, Marcela. Português: contexto, interlocução e sentido. 3 ed. São Paulo: Moderna, 2016.

ANDRADE, Oswald. Obras completas. Volumes 6-7. Rio de Janeiro: Civilização Brasileira, 1972.

BAGNO, Marcos. Sete erros aos quatro ventos: a variação linguística no ensino do português. São Paulo: Parábola Editorial, 2013.

BARRETO, Ricardo Gonçalves; BÁRBARA, Miranka Gonçalves-Santa; BERGAMIM, Cecília. EDIÇÕES SM (Org.). Ser protagonista: língua portuguesa. 3.ed. São Paulo: Edições SM, 2016. v. 1. p. 158-170. (Coleção Ser protagonista).

BORTONI-RICARDO, Stella Maris. O português brasileiro. In.: . Educação em língua marterna: a sociolinguística na sala de aula. São Paulo, Parábola, 2004, p. 53 - 70.

Editorial, 2005.

Nós cheguemu na escola, e agora? Sociolinguística e Educação. São Paulo: Parábola

BRASIL. Ministério da Educação. Secretaria de Educação Básica. Guia de livros didáticos: PNLD 2018: Ciências: Ensino Fundamental: Anos Finais. Disponível em: https://www.fnde.gov.br/index.php/programas/ programas-do-livro/pnld/guia-do-livro-didatico/item/11148-guia-pnld-2018. Acesso em 22/08/2017.

. Ministério da Educação. Passo a passo para o registro de escolha - PNLD -2018. Disponível em: https://www.fnde.gov.br/index.php/centrais-de-conteudos/publicacoes / category/125-guias?download=10750:passo-a-passo-escolha-pnld-2018. Acesso em: 22/08/2017.

. Ministério da Educação. Parâmetros Curriculares Nacionais - Ensino Médio. Disponível em: <http://portal.mec.gov.br/seb/arquivos/pdf/14_24.pdf>. Acesso em: 22/08/2017.

. Ministério da Educação. PCN Ensino Médio + Orientações Educacionais Complementares aos Parâmetros Curriculares Nacionais - Linguagens, Códigos e suas Tecnologias. Disponível em: <http://portal.mec.gov.br/seb/arquivos/pdf/linguagens02.pdf >. Acesso em: 22/08/2017.

. Ministério da Educação. Fundo Nacional de Desenvolvimento da Educação. Programa Dinheiro Direto na Escola. Disponível em: < http://www.fnde.gov.br/programas/dinheiro-direto-escola/dinheiro-direto-escola-apresen tacao >. Acesso em: 22/08/2017.

GROSJEAN, F. Life with two languages: an introduction to bilingualism. Cambrige, Massachussetts, London: Harvard University Press, 2001 [1982]. 
LABOV, Willian. Padrões sociolinguísticos. Tradução de Marcos Bagno, Maria Marta Pereira Scherre e Cardoso, Caroline Rodrigues. São Paulo: Parábola, 2008 [1972].

ORMUNDO, Wilton; SINISCALCHI, Cristiane. Se liga na lingua: literatura, produção de texto e linguagem. São Paulo: Moderna, 2016. v. 1. p. 238-255; p. 272-277. (Coleção Se liga na língua).

RIBEIRO, Ivone; SETTE, Graça; STARLING, Rozário; TRAVALHA, Márcia. Português: trilhas e tramas. 2. ed. São Paulo: Leya, 2016. v. 1. p. 204-211. (Coleção Trilhas e tramas) ; Português: trilhas e tramas. 2. ed. São Paulo: Leya, 2016. v. 3. p. 278-287. (Coleção Trilhas e tramas).

WEINREICH, Uriel; LABOV, William; HERZOG, Marvin. Fundamentos empiricos para uma teoria da mudança linguística. São Paulo: Parábola, 2006 [1968]. (Tradução de Marcos Bagno).

Recebido em: 29/05/2020. Aprovado em: 14/06/2020. 
ANEXO A - Formulário de Percepção - elaborado pelas autoras.

Escola:

\section{FORMULÁRIO DE PERCEPÇÃO}

Nome:

Idade:

Série:

Bairro em que mora: Cidade/estado de origem:

Nome do responsável: Profissão:

Nome do responsável: Profissão:

Há quanto tempo mora no ES? R:

Você já ficou reprovado? Se sim, por quê?

1) Quando você ouve falar em língua portuguesa, quais palavras vêm à sua mente? Escreva no máximo 5 palavras.

2) O que você acha do ensino da língua portuguesa na escola?

3) Considerando que você ingressou na escola já sabendo falar português, como você entende a necessidade de estudar o português na escola?

4) Como você avalia a sua forma de falar em relação ao português ensinado na escola?

5) Você acha importante aprender na escola as diferentes formas de falar o português? 
ANEXO B - Relação de palavras observadas nos formulários de percepção e seus respectivos quantitativos de ocorrência - disposição em ordem alfabética - resposta questão 01 do formulário de percepção

\section{PALAVRA/OCORRÊNCIAS}

Acentuação/1

Adjetivos/1

Advérbio/2

Aglutinação/2

Alegria/1

Amanhecer/1

Amor/1

Aprender/Aprendizado/6

Atividade/1

Brasil/5

Caderno/1

Cansativo/1

Carácter/1

Chato/7

Classicismo/2

Comunicação/1

Conhecer/1

Conjunção/1

Cultura/1

Diálogo/4

Dicionário/1

Difícil/2

Disciplina/1

Ditongo/1

Doutora/1

Educação/5

Enem/1

Engraçado/1

Ensinamento/1

Entendimento/1

Escola/4

Escrever/4

Escritores/1

Estudo/1

Exercício/4

Explicação/1
Falar/1

Feminismo/1

Gramática/2

Hiato/1

Histórias/1

Horrível/1

Humanismo/1

Idiomas $/ 2$

Inint/3

Insuportável/1

Interação/1

Interessante/3

Interpretação/3

Introdução/1

Junções $/ 1$

Legal/3

Leitura/ 6

Leonardo Da Vinci/1

Língua/Línguas/Lingua-

gem $/ 4$

Literatura/Lit. Brasi-

leira/ 8

Livro/6

Maravilhoso/1

Matéria/2

Necessidade/1

Nome de Professor/9

Novidade/1

O Que/1

Onde/1

Palavras Difíceis/1

Palavras Novas/1

Palavras/1

Parassintética/1

Paroxítona/2

Perguntas/1
Ponto/1

Portugal/3

Prefixal/Prefixo/2

Preguiça/1

Professor(a)/1

Profissão/1

Proparoxítona/1

Prova/3

Quando/1

Redação/2

Reflexão/1

Renascimento/2

Respeito/1

Responsabilidade/1

Saber/1

Significado/1

Sílaba Tônica/1Substantivo/2Sufixal/Sufixo/

2Tédio/1

Tempo/1

Texto $/ 8$

Trovadorismo/1

Verbo/4

Vírgula/1 